IDEAS IN ECRLGGY AND EVILUTION 4: 34-36, 2011

doi:10.4033/iee.2011.4.6.e

(C) 2011 The Author. (C) Ideas in Ecology and Evolution 2011 Received 3 December 2011; Accepted 3 December 2011

\title{
Editarial
}

\section{Creative science in theory and practice}

\section{Bernard Crespi}

Bernard Crespi (crespi@sfu.ca), Department of Biosciences, Simon Fraser University, Burnaby, British Columbia, Canada

Bill Hamilton once explained to me his philosophy of scientific practice: building dizzying scaffolds of novel thought held together tenuously, at first, by theory and assumption. If the scaffold can support empirical data, then science has progressed by a bold, quantum leap upwards; if not, the whole edifice crashes in spectacular ruins, with damage mainly to pride or ego. He contrasted this scaffold model with one of masonry: collecting data brick by brick to build slowly upon a pre-existing, firm yet unexciting foundation. Solid progress, but nothing new, nothing inspiring, nothing... creative.

New ideas in ecology and evolution emerge from creative thought, from scaffolds that reach upwards and across disciplines. From where, then, does scientific creativity spring? And, if we know, can we deliberately seek to become more creative, and emulate scientists like Hamilton, Trivers, Hutchinson, MacArthur, or Darwin?

Scientific creativity has been studied in two primary domains. First, the causes and correlates of such creativity have themselves been studied, to develop and evaluate models for what makes some scientists more creative than others. Second, the psychological underpinnings of creativity have been analyzed, more broadly, as facets of natural human cognitive variation. Such psychological studies tend to focus on extremes of cognition and associated creativity, with emphasis on aspects of the psyche that underpin and foster creative insights or processes.

\section{Creative scientists}

Key correlates of creativity in scientists, as described by Dean Simonton, who has devoted his career to this topic (see Simonton 2004), include having wide-ranging interests, reading voraciously even in areas tangential or removed from one's main area of research, and writing large numbers of articles, such that creativity is strongly, positively associated with lifetime productivity. Perhaps surprisingly, general intelligence, as indexed by IQ, is only weakly associated with creativity, and then only for the IQ range below 120 . Over 120, where the great majority of academic scientists hopefully score, creativity is uncorrelated with IQ.

Our first lesson for increasing creativity in ecology and evolution is thus to read and think broadly and widely, and avoid overspecialization-an increasing danger as the scientific literature burgeons year by year. Read New Scientist and Nature, and even books (books?!) on topics of interest that are not within your core domain of inquiry. To be interesting, be interested in a variety of fields, across taxa, from molecular genetics to philosophy.

Back in the 1980s-before computers transformed most areas except scientific creativity-our muse, Bill Hamilton, had an extensive card filing system for his references, with illegible (to me) notes on each. One day, leaning over and thumbing through the cards, he looked up and softly opined: "these are the neurons of my brain." So too will all of your extensive reading and your filing system, come to represent the raw materials of your scientific brain and thoughts. Bill indeed once referred to himself as an "unrepentant library mole." With the world's literature now at our keyboards rather than file cards, opportunities for scientific digging and exploring have never been more exciting or open-ended.

The second lesson, high productivity, appears more difficult, but it directs us to focus on the need to write consistently and persistently, with discipline, strong 
coffee, and likely, considerable psychic pain. Writing is an act of creation, and is the scientific bottom line. Never publish it — even on a blog — and it never existed; it was a waste of your time and someone's money. You will die, but ideas are immortal and can change the world.

Explicit models of how creativity works have been developed from studies of creative people and the genesis of their new ideas. Common features across such models include:

- curiousity, motivation, and toleration for ambiguity and uncertainty;

- generation of new ideas, which involves fluent exploration of ideational space, and novel combination and cross-referencing of thoughts and facts from across myriad domains - processes that involve divergent and defocussed thought, like a mental wander across a Wrightian adaptive landscape in search of higher peaks; and

- recognition and mental-Darwinian natural selection of the most-promising new ideas.

Hamilton's 1967 paper on Extraordinary Sex Ratios provides a simple example of this process: his years of "mole-ing" through the literature unearthed examples, from across disparate taxa, of insects that (1) lived in claustral, enclosed habitats, (2) exhibited wingless males, and (3) showed female biases in their sex ratios. What selective pressures could produce such convergence? Hamilton combined nascent gene-centred, inclusive-fitness thought with the idea of selection for female-biased sex ratios in such habitats, to create the field of sex ratio theory, and the first evolutionarily stable strategy model.

\section{Creative psyches}

Models of creativity, and study of relatively creative scientists, are complemented by studies of the psychological underpinnings of creativity, with a focus on psychiatric conditions that appear to be associated with forms of creative thought and productivity. Much of this work has centred on individuals exhibiting psychological traits on the 'psychotic-affective spectrum', which includes the overlapping, highly-heritable conditions schizophrenia, bipolar disorder, and major depression. Each of these conditions exists, in its constellation of psychological phenotypes, on a continuum ranging from severe clinical impairment to what passes for normality (Bentall 2003). Thus, you and I are more or less schizotypal, occasionally somewhat manic, or tending to anxious or depressed. It is these personality traits, not madness, mania, or sadness themselves, that have been analyzed in association with creativity.
Schizophrenia-like cognition has been well-documented to engender strong imagination, divergent thinking, and 'loose' associations among thoughts and words, all traits that can enhance the 'exploration' phase of creativity and foster problem-solving that requires novel insights (e. g., Nettle 2001; Barrantes-Vidal 2004; Karimi et al. 2007). By contrast, mild forms of bipolardisorder mania (referred to as hypomania) are notably associated with prodigious creative productivity, and often genius, apparently due in large part to increased goal-seeking and motivation coupled with high energy levels and positivity (Jamison 1993). Depressive temperaments have a less obvious connection with creativity. Some authors have suggested that the same generative brain regions are activated in creative thought as in depressive rumination, or, have linked creativity with depressive episodes over the long term (Flaherty 2005). For each of these conditions, relatively high (although not stellar) IQ may be pre-requisite for effects on scientific or artistic creativity: think John Nash's 'beautiful mind', or Albert Einstein's and James Watson's children with schizophrenia - each of the three an insightful, creative genius with alleles 'for' schizophrenia.

In contrast to creative, psychotic-affective personalities, autistic genius is usually characterized in terms of savant skills: remarkable, highly-specialized skills in a small set of areas including mathematical computation, rote memory, calendar calculating, perspective drawing, and absolute pitch (Happé and Frith 2010). Such extreme skills are usually lockstep with autistic social disabilities, and are usually not considered creative per se. Indeed, they appear opposite to novelty: individuals with autism show restricted interests and repetitive behavior - many also insist on sameness in their environment. But what of less-extreme autistic traits and skills? Autistic cognition has also been strongly associated with high levels of abstract, 'fluid' intelligence (Dawson et al. 2007; Hayashi et al. 2008), and enhanced visual-spatial skills, including aspects of mathematics and engineering (Baron-Cohen et al. 2001; Mottron et al. 2006; Nettle 2006), especially those involved in analyzing the workings and rules of 'systems' (Baron-Cohen 2006). Individuals with autistic personalities may thus be no less creative than their psychotic-affective-personality counterparts-just differently creative.

Autism is also highly heritable, and since we are stuck with our personal three billion base pairs from mother and dad, how do such psychological considerations affect our quest for enhanced creativity? Mainly, I think, through self-knowledge-knowing better our own mind's position on an axis from psychoticaffective, through normal, to autistic cognition (Crespi and Badcock 2008). Such information allows better 
recognition of our own skill sets, and suggests how best to design one's career and target development of creative abilities. Indeed, a recent brain imaging study suggests tradeoffs between performance of divergent (open-ended) versus convergent (closed-ended) tasks (Chrysikou \& Thompson-Schill 2011); how important are such tradeoffs in cognitive skills, and how do they impact performance in science? Most generally, still believing in Santa at thirty might bode better for focusing on scientific questions that require imaginative leaps, while autistic tendencies should better serve systematic, rule-governed and memory-based work. Do molecular ecologists differ from evolutionary theoreticians on scales of autism or schizotypy? Only a creative study will tell.

Science may be, or should be, a deeply creative enterprise, and the scientific study of creativity has yet to permeate far into its evolutionary or neurologicalpsychological roots. But for the future of humanity, if not our own careers, increased creativity provides a fundamental way onward, built with scaffolds of thought, and using some of the tools that we have discussed here.

\section{References}

Baron-Cohen, S., Wheelwright, S., Skinner, R., Martin, J. and E. Clubley. 2001. The autism-spectrum quotient (AQ): Evidence from Asperger syndrome/ high-functioning autism, males and females, scientists and mathematicians. Journal of Autism and Developmental Disorders 31:5-17. CrossRef

Baron-Cohen, S. 2006. Two new theories of autism: Hyper-systemising and assortative mating. Archives of Disease in Childhood 91:2-5. CrossRef

Barrantes-Vidal, N. 2004. Creativity and madness revisited from current psychological perspectives. Journal of Consciousness Studies 11:58-78.

Bentall, R. P. 2003. Madness Explained: Psychosis and Human Nature. Allen Lane, London.

Chrysikou E.G., and S.L. Thompson-Schill. 2011. Dissociable brain states linked to common and creative object use. Human Brain Mapping 32:665675. CrossRef
Crespi, B. and C. Badcock. 2008. Psychosis and autism as diametrical disorders of the social brain. Behavioral and Brain Sciences 31:241-320. CrossRef

Dawson, M., Soulieres, I., Gernsbacher, M.A. and L. Mottron. 2007. The level and nature of autistic intelligence. Psychological Science 18:657-662. CrossRef

Flaherty A.W. 2005. Frontotemporal and dopaminergic control of idea generation and creative drive. Journal of Comparative Neurology 493:147-153. CrossRef

Hamilton, W. 1967. Extraordinary sex ratios. Science 156: 477-488. CrossRef

Happé, F. and U. Frith. 2010. Autism and Talent. Oxford University Press, Oxford.

Hayashi, M., Kato, M., Igarashi, K. and H. Kashima. 2008. Superior fluid intelligence in children with Asperger's disorder. Brain and Cognition 66:306310. CrossRef

Jamison, K.R. 1993. Touched with Fire: ManicDepressive Illness and the Artistic Temperament. Free Press, New York.

Karimi, Z., Windmann, S., Gunturkun, O., and A. Abraham. 2007. Insight problem solving in individuals with high versus low schizotypy. Journal of Research in Personality 41: 473-480. CrossRef

Mottron L, Dawson M, Soulières I, Hubert B, and J. Burack. 2006. Enhanced perceptual functioning in autism: an update, and eight principles of autistic perception. Journal of Autism and Developmental Disorders 36:27-43. CrossRef

Nettle, D. 2001. Strong Imagination: Madness, Creativity and Human Nature. Oxford University Press, Oxford.

Nettle, D. 2006. Schizotypy and mental health amongst poets, visual artists, and mathematicians. Journal of Research in Personality 40:876-890. CrossRef

Simonton, D.K. 2004. Creativity in Science: Chance, Logic, Genius, and Zeitgeist. Cambridge University Press, Cambridge. 